Title:

A New Approach to Texture Measurements:

Orientation Distribution Function (ODF)

Determination by Rietveld Refinement

Author(s):

Robert Vondreele, MLNSC

Allen Larson, MLNSC

Andrew Lawson, MST-5

Robert Sheldon, NMT-9

Stuart Wright, DOE/EXT

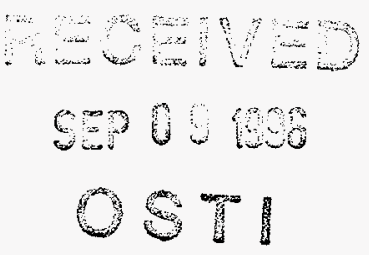

Submitted to:

DOE Office of Scientific and Technical Information (OSTI)
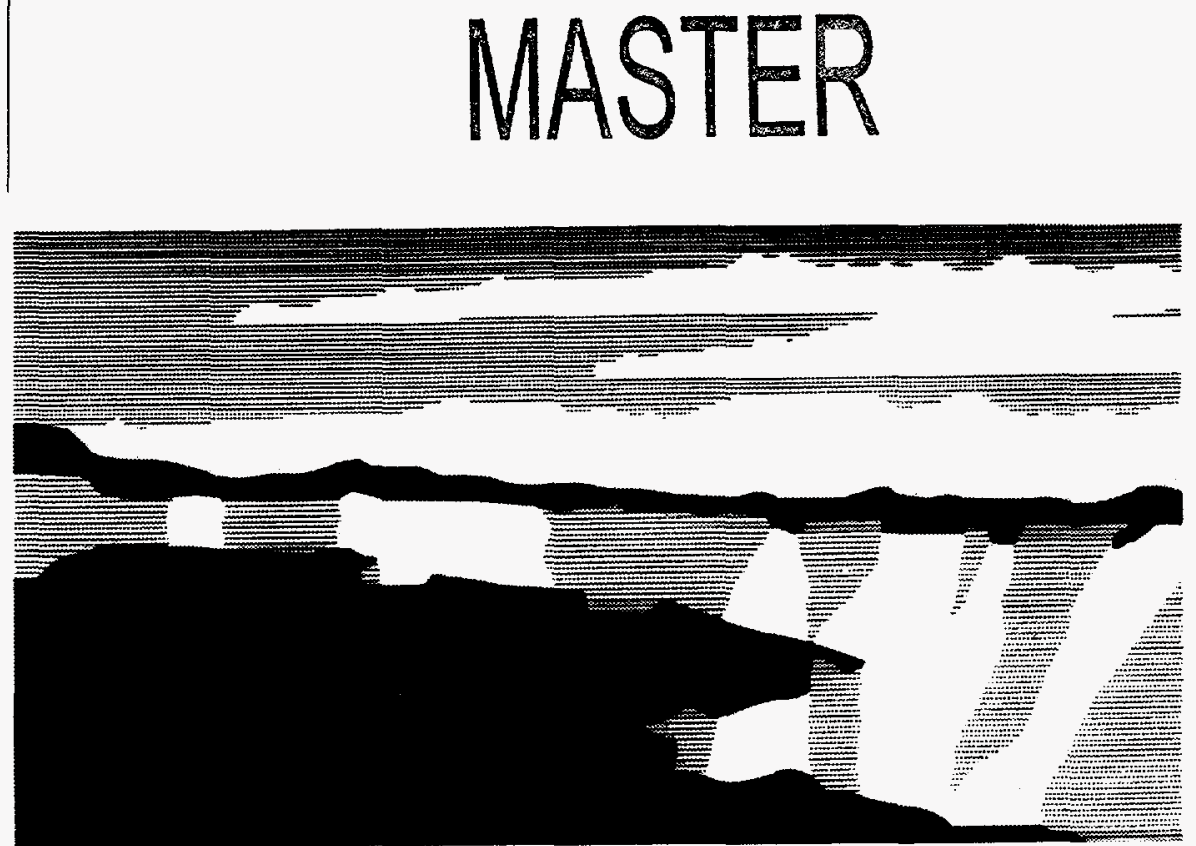

Los Amos National Laboratory, an affirmative action/equal opportunity employer, is operated by the University of Califomia for the U.S. Department of Enexw inder contract W-7405-ENG-36. By acceptance of this article, the publisher recognizes that the U.S. Government retains a nonexclusive, royaltytreee se publish or reproduce the published form of this contribution, or to allow others to do so, for U.S. Government purposes. The Los Alamos Nation aboratory requests that the publisher identify this article as work performed under the auspices of the U.S. Department of Energy. 


\section{DISCLAIMER}

Portions of this document may be illegible in electronic image products. Images are produced from the best available original document. 


\title{
A New Approach to Texture Measurements: Orientation Distribution Function (ODF) Determination by Rietveld Refinement
}

\author{
Robert Vondreele*, Allen Larson, Andrew Lawson, Robert Sheldon, and \\ Stuart Wright
}

\begin{abstract}
This is the final report of a three-year, Laboratory-Directed Research and Development (LDRD) project at the Los Alamos National Laboratory (LANL). This project sought to develop the experimental procedures and the mathematical treatment needed to produce an orientation distribution function (ODF) directly from full diffraction patterns from a sample in a limited number of orientations.
\end{abstract}

\section{Background and Research Objectives}

Many technologically important materials are subject to manufacturing processes that mpart to the material a preferred orientation of the individual crystal grains within the material. The orientation of the grains can have a profound effect on the physical properties of a nanufactured part affecting both its strength and possible failure modes. In the case of zomposite materials, which by proper combination of components can yield very high strength naterials with light weight, the preferred orientation of both components with respect to each ther as well as to the exterior dimensions of the part can strongly affect how well the :omponent performs in service. In fact, the performance of a part made with composite naterials can be enhanced by proper selection of a preferred orientation for the components. Moreover, in the case of new high $\mathrm{T}_{\mathrm{C}}$ superconducting oxides, the preferred orientation has a Jrofound effect on the electrical conduction in wires and other components made with these naterials. For example, the crystal grains must be very highly oriented within a wire for it to sarry appreciable current densities and much of the present development effort has been ocused on achieving high preferred orientation in the finished wire. Present efforts in this irection are to develop a wire consisting of highly oriented oxide contained within a silver netal sheath. To achieve high superconducting currents, the oxide must be oriented with the

\footnotetext{
:Principal investigator, e-mail: vondreele@lanl.gov
} 
ong crystallographic axis (usually the c-axis of a tetragonal cell) normal to the wire. Evaluation of this texture by $\mathrm{x}$-ray methods is difficult because of the extremely poor zenetrating power of $x$-rays. The silver sheath is essentially opaque to $x$-rays so that sample zreparation for conventional pole figure measurements involve removal of the sheath by :hemical or mechanical means. This process can strongly alter the state of the oxide superconductor that is inside the wire thus invalidating the texture measurement. Moreover, ine sample dimensions used in conventional x-ray analysis (typically 25-mm diameter disks) :equire a complex series of steps to properly orient an array of many wires so that the texture :an be properly measured. Thus, methods of rapidly characterizing the preferred orientation of 'raw" samples not subjected to elaborate preparation are essential to help guide the Sevelopment of these materials into technologically useful components.

The preferred orientation of crystal grains within a manufactured part is described most Illy by its orientation distribution function (ODF), which is a mapping of the probability of sach of the possible grain orientations with respect to the exterior dimensions. Traditionally, in ODF is determined from pole figures for a relatively small number of reflections. These zole figures are measured with $\mathrm{x}$-rays or neutrons using short detector scans over the center of in individual diffraction peak for a large number of different sample orientations. This is sficient if the selected diffraction peaks are reasonably strong (relative to background) and well separated, such as in pure fcc and bcc metals. It is also appropriate for constant wavelength sources where collection of individual diffraction peak intensities is a reasonably efficient use if the source. However, the traditional method is not very efficient for neutron diffraction at a spallation source such as LANSCE (Los Alamos Neutron Science Center) where the entire iffraction pattern is accessible for each sample setting. Moreover, a different approach is secessary for complicated diffraction patterns, such as from composite materials, intermetallic :ompounds, high $\mathrm{T}_{\mathcal{C}}$ ceramics, polyphasic minerals and polymers where there is expected to be reavy overlap of adjacent diffraction peaks. In addition, the large number of settings normally sollected for an individual pole figure may not be necessary, since the entire pattern is obtained

it each setting. Thus, a new method of ODF analysis needs to be developed to handle the more :omplex diffraction patterns obtained from modern technological materials as well as take idvantage of the particular characteristics of spallation neutron sources.

\section{$\therefore \quad$ Importance to LANL's Science and Technology Base and National R\&D Needs}

The development of a simple experimental procedure and mathematical treatment ıeeded to produce an orientation distribution function directly from full diffraction patterns will 
idvance the development of sophisticated materials such as high $T_{\mathcal{C}}$ superconducting wires and jigh strength composite materials. This project supports the Los Alamos core competency in zuclear and advanced materials.

\section{Scientific Approach and Results to Date}

Our experimental approach is to obtain diffraction data on a number of "standard" exture samples and more complex test specimens of, for example, granites, composite zaterials and high Tc ceramic components using the High Intensity Powder Diffractometer HIPD) at LANSCE. During the first two years of the project, we completed measurements on several test specimens including 18 different settings of a hot-pressed alumina plate (NIST SRM 1976 intensity/texture standard), a 1/4" rolled stainless steel plate, a 1/4" stainless/carbon steel/stainless "sandwich" rolled plate, and several cross-rolled titanium plates, all of which somprise some 800 individual data sets. During the final year we have collected additional data sets with which to test the new spherical harmonic Rietveld refinement code. This includes a sexamination of the steel sandwich, new data from a rolled aluminum plate, a nanocrystalline suminum rod, a shocked titanium plate, some tungsten rods to be used in the new LANSCE groduction target, niobium/copper alloy rod and silver/copper alloy rod, and some uranium/niobium alloy plates. This suite of data (from approximately 25 samples and :omprising roughly 2400 individual patterns) is the test set for the code developed for ODF ذetermination.

Our data analysis approach initially included the tools to extract full sets of intensities or all phases in a multicomponent sample for possible ODF determination from pole figures. This was successfully done using the "le Bail" method for extracting intensities from powder jatterns. The method works quite well for multicomponent mixtures and has found sonsiderable use in the solution of crystal structures from powder data. However, we have not ?ursued the use of these intensities for ODF determination since that approach does not lead to $\imath$ rapid ODF determination method. To achieve this goal, we have proposed the simultaneous Levelopment of direct modeling of the ODF in the Rietveld refinement software. A major uchievement has been the implementation of the generalized spherical harmonic description of exture into the Rietveld code GSAS operating on personal computers. This model was ieveloped to be applicable to any crystal symmetry and to the most common sample iymmetries (fiber, rolling, shear and centric symmetries) in as many as nine phases in a solycrystalline sample. Currently the maximum order of the harmonics is $L=34$ and up to 600 armonic coefficients can, in principle, be refined for each phase. This analysis has been ested against most of the data collected and pole figures calculated from the refined coefficients 
generally are satisfactory. As an example the (100) pole figure (Figure 1) of upforged tantalum netal was computed from the spherical harmonics coefficients determined in a Rietveld :efinement of 46 powder diffraction patterns collected from a single cylindrical sample held in a variety of orientations in the neutron beam. This pole figure is virtually identical to that sbtained by more conventional means with both neutron and $\mathrm{x}$-ray diffraction.

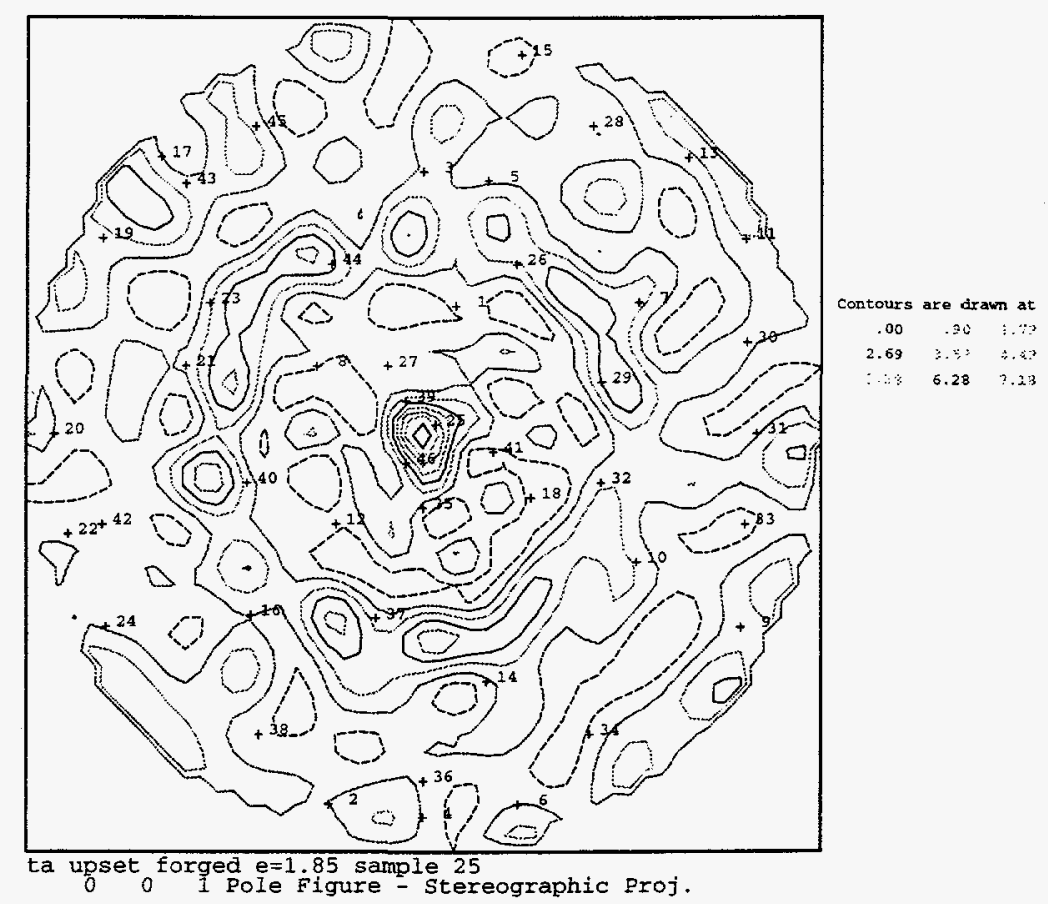

Figure 1. The (100) pole figure computed from 205 spherical harmonic coefficients :etermined via Rietveld refinement with 46 neutron TOF neutron powder diffraction patterns.

One related problem is the modeling of the strains that are associated with texture. Since strains affect the powder pattern by shifting the peak positions, a model to accommodate his effect is needed to prevent systematic errors in the intensity measurements associated with JDF determination. To deal with the effect of strain we have implemented a simple model that illows the strain to be described as having an isotropic and an anisotropic component. One Inexplored facet of this simultaneous determination of strain and texture is the coupling of hese two effects within a complete theoretical framework for the response of a material to a oad. 


\section{DISCLAMER}

This report was prepared as an account of work sponsored by an agency of the United States Government. Neither the United States Government nor any agency thereof, nor any of their employees, makes any warranty, express or implied, or assumes any legal liability or responsibility for the accuracy, completeness, or usefulness of any information, apparatus, product, or process disclosed, or represents that its use would not infringe privately owned rights. Reference herein to any specific commercial product, process, or service by trade name, trademark, manufacturer, or otherwise does not necessarily constitute or imply its endorsement, recommendation, or favoring by the United States Government or any agency thereof. The views and opinions of authors expressed herein do not necessarily state or reflect those of the United States Government or any agency thereof. 